\title{
PENGARUH PENGGUNAAN KOLKISIN TERHADAP PERTUMBUHAN VEGETATIF TANAMAN SEDAP MALAM (Polianthes tuberose L.) DI DATARAN MEDIUM
}

\author{
Yekti Sri Rahayu ${ }^{1}$ Istiyono K. Prasetyo ${ }^{1}$ Andrys Umbu Riada ${ }^{1}$ \\ ${ }^{1)}$ Agriculture Faculty of Univ. Wisnuwardhana Malang \\ Email : yektisr@ymail.com
}

\begin{abstract}
ABSTRAK
Tanaman hias sedap malam di daerah Bangil Pasuruan selama ini dikenal dengan ciri khas bunganya yang kecil namun harum. Upaya perbaikan kualitas dan upaya pengembangan bunga sedap malam di dataran medium terus dilakukan dengan menciptakan pertumbuhan tanaman yang lebih baik. Tujuan penelitian ini adalah untuk mengetahui pengaruh pemberian kolkisin terhadap pertumbuhan vegetatif tanaman sedap malam yang ditanam didataran medium kota Malang. Penelitian ini dilakukan secara eksperimen di kelurahan Cemorokandang, kecamatan Kedungkandang, Malang, yang memiliki ketinggian tempat $610 \mathrm{~m}$ dpl., pada bulan Mei sampai Nopember 2013. Rancangan yang digunakan adalah Rancangan Acak Kelompok yang diulang tiga kali. dan terdiri dari dua faktor, faktor pertama adalah lama perendaman (W) : 3 jam (W1); 6 jam (W2); 9 jam (W3); dan 12 jam (W4). Faktor kedua adalah tingkat konsentrasi kolkhisin: 0 ppm (P0); 100 ppm (P1); 300 ppm (P2); dan 500 ppm (P3). Pengamatan dilakukan terhadap karakteristik pertumbuhan tanaman sedap malam pada fase vegetatif diantaranya meliputi panjang tanaman, jumlah daun, luas daun, jumlah anakan. Data hasil penelitian dianalisis dengan analisis sidik ragam sesuai dengan rancangan yang digunakan, dan jika terdapat pengaruh nyata dilanjutkan dengan Uji Jarak Duncan (DMRT) pada taraf 5\%. Hasil penelitian menunjukkan bahwa pengaruh tingkat konsentrasi kolkisin dan lama perendaman secara umum tidak memberikan pengaruh nyata terhadap rerata panjang tanaman sedap malam, namun secara terpisah pemberian kolkisin pada tingkat konsentrasi 100 ppm hingga 500 ppm menghasilkan rerata panjang tanaman yang lebih tinggi dibanding tanpa pemberian kolkisin. Pengaruh tingkat konsentrasi kolkisin dan lama perendaman secara umum memberikan pengaruh nyata pada jumlah daun dan luas daun, dimana secara umum pada tingkat konsentrasi kolkisin 300 ppm dengan lama perendaman 6 jam dan tingkat konsnetrasi 100 ppm dengan lama perendaman 9 jam menghasilkan rerata jumlah daun dan luas daun yang lebih tinggi. Pengamatan terhadap jumlah anakan tanaman sedap malam menunjukkan pada tingkat konsentrasi 100 ppm dengan lama perendaman 9 jam dan pada konsentrasi 300 ppm dengan lama perendaman 9 dan 6 jam menghasilkan rerata jumlah anakan yang lebih banyak.
\end{abstract}

Kata kunci: pertumbuhan vegetatif, tanaman sedap malam, kolkisin

\section{PENDAHULUAN}

Penanaman tanaman sedap malam

khususnya varietas Roro anteng belum banyak dilakukan di dataran medium. Selama ini tanaman sedap malam varietas Roro Anteng lebih dikembangkan secara luas di daerah dataran rendah khususnya di daerah Bangil Pasuruan. Padahal jika menilik pada daya adaptasinya, menurut Plantus (2008) tanaman sedap malam termasuk salah satu jenis flora introduksi dari Amerika yang memliki kemampuan adaptasi dengan baik di daerah beriklim panas (tropis), dan di Indonesia cocok 
dikembangkan di dataran menengah sampai tinggi.

Upaya pengembangan tanaman sedap malam terus dilakukan mengingat ekspektasi kebutuhan akan tanaman sedap malam sebagai tanaman hias baik sebagai bunga potong maupun kebutuhan untuk industri yang cukup tinggi. Kekhawatiran masyarakat akan kemampuan tumbuh tanaman sedap malam di dataran yang lebih tinggi selain daerah pengembangannya selama ini di dataran rendah tidak cukup beralasan karena masih jarangnya penelitian yang dilakukan untuk hal tersebut.

Untuk itu penelitian ini dilakukan selain untuk mengetahui kemampuan tumbuh tanaman sedap malam di dataran medium, juga untuk mengetahui pengaruh dari aplikasi pemberian kolkisin pada tanaman sedap malam yang ditanam di dataran medium. Harapan dari penelitian ini adalah upaya perbaikan pertumbuhan secara mutasi genetic melalui penggunaan kolkisin dan interaksi tanaman dengan kondisi agroekologi di dataran medium memberikan respon yang baik bagi pertumbuhannya. Penggunaan kolkisin diberikan mengingat kemampuan kolkisin sebagai bahan mutagen pada tanaman, selama ini telah banyak dibuktikan dapat memberikan pengaruh nyata pada beberapa tanama. Pemberian bahan mutagen seperti kolkisin adalah untuk mutasi yang menyebabkan terjadinya poliploid dimana organisme memiliki tiga atau lebih kromosom dalam sel-selnya, dimana sifat umum tanaman hasil poliploidisasi secara umum adalah menjadi lebih kekar, bagian tanaman lebih besar (akar, batang,daun,bunga,dan buah), sehingga nantinya sifat-sifat yang kurang baik akan menjadi lebih baik tanpa mengubah potensi hasilnya (Hieter \&Griffiths,1999 dalam Sulistianingsih, 2004).

\section{BAHAN DAN METODE}

Penelitian ini dilakukan di lapang, di kelurahan Cemorokandang, kecamatan Kedungkandang Kota Malang dengan ketinggian tempat sekitar $610 \mathrm{~m}$ dpl pada bulan Mei hingga Nopember 2013. Rancangan yang digunakan adalah Rancangan Acak Kelompok, yang terdiri dari dua faktor, faktor pertama adalah lama perendaman (W) : 3 jam (W1); 6 jam (W2); 9 jam (W3); dan 12 jam (W4). Faktor kedua adalah konsentrasi kolkhisin: 0 ppm (P0); 100 ppm (P1); 300 ppm (P2); dan 500 ppm (P3). Masing-masing perlakuan diulang sebanyak 3 kali, sehingga dalam penelitian ini terdapat 48 unit percobaan. Aplikasi perlakuan diberikan dengan cara merendam umbi tanaman sedap malam dalam larutan kolkisin dengan konsentrasi dan lama perendaman sesuai dengan perlakuan yang diberikan. Pengamatan dilakukan terhadap karakteristik pertumbuhan tanaman sedap malam pada fase vegetatif diantaranya meliputi panjang tanaman, jumlah daun, luas daun, dan jumlah anakan. Data yang 
diamati dari hasil penelitian dianalisis dengan analisis sidik ragam sesuai dengan rancangan yang digunakan, jika terdapat pengaruh nyata dilanjutkan dengan $\mathrm{Uji}$ Jarak Duncan (DMRT) pada taraf 5\%.

\section{HASIL DAN PEMBAHASAN}

Hasil pengamatan terhadap pertumbuhan vegetatif tanaman secara umum menunjukkan adanya pengaruh interaksi antara tingkat konsentrasi dan lama perendaman terhadap jumlah daun, luas daun dan jumlah anakan. Sementara pada panjang tanaman, tingkat konsentrasi dan lama perendaman secara umum tidak memberikan pengaruh nyata.

Panjang Tanaman

Hasil analisis ragam menunjukkan bahwa secara umum interaksi antara tingkat konsentrasi dan lama perendaman kolkisin tidak memberikan pengaruh yang nyata terhadap panjang tanaman sedap malam. Namun pada umur 70, 98, 126, dan146 hst tingkat konsentrasi kolkisin secara terpisah memberikan pengaruh nyata pada panjang tanaman sedap malam.

Tabel 1. Rerata panjang tanaman sedap malam (cm) umur 70 samapai 140 hst berdasarkan tingkat konsentrasi dan lama perendaman kolkisin

\begin{tabular}{|c|c|c|c|c|c|}
\hline \multicolumn{6}{|c|}{ Rerata Panjang Tanaman Umur (HST) } \\
\hline \multicolumn{2}{|c|}{ Perlakuan } & 70 & 98 & 126 & 140 \\
\hline \multirow{4}{*}{$\begin{array}{l}\text { Tingkat } \\
\text { konsentrasi } \\
(\mathrm{ppm})\end{array}$} & 0 & $18.14 \mathrm{a}$ & $22.14 \mathrm{a}$ & $23.43 \mathrm{a}$ & $23.83 \mathrm{a}$ \\
\hline & 100 & $24.06 \mathrm{~b}$ & $27.46 \mathrm{~b}$ & $28.79 \mathrm{~b}$ & $29.61 \mathrm{~b}$ \\
\hline & 300 & $21.91 \mathrm{~b}$ & $24.51 \mathrm{ab}$ & $27.06 \mathrm{ab}$ & $27.39 \mathrm{ab}$ \\
\hline & 500 & $22.80 \mathrm{~b}$ & $25.35 \mathrm{ab}$ & $28.16 \mathrm{~b}$ & $28.78 \mathrm{~b}$ \\
\hline \multirow{4}{*}{$\begin{array}{l}\text { Lama } \\
\text { perendaman } \\
\text { (jam) }\end{array}$} & 3 & $23.65 \mathrm{a}$ & $26.70 \mathrm{a}$ & $28.93 \mathrm{a}$ & $29.52 \mathrm{a}$ \\
\hline & 6 & $21.53 \mathrm{a}$ & $24.80 \mathrm{a}$ & $25.90 \mathrm{a}$ & $26.72 \mathrm{a}$ \\
\hline & 9 & $20.77 \mathrm{a}$ & $24.61 \mathrm{a}$ & $26.86 \mathrm{a}$ & $27.16 \mathrm{a}$ \\
\hline & 12 & $20.96 \mathrm{a}$ & $23.35 \mathrm{a}$ & $25.75 \mathrm{a}$ & $26.20 \mathrm{a}$ \\
\hline \multicolumn{2}{|c|}{$P$} & $*$ & $*$ & $*$ & $*$ \\
\hline \multicolumn{2}{|c|}{$\mathrm{W}$} & Ns & Ns & Ns & Ns \\
\hline \multicolumn{2}{|c|}{$\mathrm{PxW}$} & Ns & Ns & $\mathrm{Ns}$ & $\mathrm{Ns}$ \\
\hline
\end{tabular}

Keterangan: angka yang diikuti huruf yang sama pada kolom yang sama tidak berbeda nyata pada uji Jarak Duncan 5\%

Tabel 1 menunjukkan bahwa pada umur 70 hingga 140 hst, pemberian kolkisin pada tingkat konsentrasi 100 ppm - 500 ppm menghasilkan rerata panjang tanaman yang lebih tinggi dibandingkan dengan tanaman kontrol. Pada umur 70 hingga 140 hst, pemberian kolkhisin pada tingkat konsentrasi 100 ppm menghasilkan rerata panjang tanaman sedap malam yang tidak berbeda nyata dengan tanaman yang diberi kolkisin pada tingkat konsentrasi 300 ppm dan 500 ppm. 


\section{Jumlah Daun}

Hasil analisis ragam menunjukkan bahwa interaksi antara tingkat konsentrasi kolkisin dan lama perendaman secara umum memberikan pengaruh nyata pada jumlah daun tanaman sedap malam yakni dapat dilihat pada umur pengamatan 14,42 , 84, 98, 112 dan 126 hari setelah tanam (hst).

Tabel 2. Rerata jumlah daun tanaman sedap malam akibat interaksi antara tingkat konsentrasi dan lama perendaman kolkhisin umur 14, 42, 84, 98, 112, dan 126 hst.

\begin{tabular}{|c|c|c|c|c|}
\hline \multicolumn{5}{|c|}{ Rerata Jumlah Daun (helai) Umur 14 hst } \\
\hline \multirow{2}{*}{$\begin{array}{c}\text { Tingkat } \\
\text { konsentrasi }(\mathrm{ppm})\end{array}$} & \multicolumn{4}{|c|}{ Lama perendaman (jam) } \\
\hline & 3 & 6 & 9 & 12 \\
\hline 0 & $3.58 \mathrm{~cd}$ & $2.50 \mathrm{ab}$ & $2.75 \mathrm{abc}$ & $2.17 \mathrm{a}$ \\
\hline 100 & $3.25 \mathrm{bcd}$ & $3.08 \mathrm{abcd}$ & 2.83 abcd & $2.25 \mathrm{ab}$ \\
\hline & $2.67 \mathrm{ab}$ & $5.08 \mathrm{e}$ & $3.58 \mathrm{~cd}$ & 3.00 abcd \\
\hline 500 & $3.83 \mathrm{~d}$ & \multirow[t]{2}{*}{$2.83 \mathrm{abcd}$} & $2.92 \mathrm{abcd}$ & $3.17 \mathrm{abcd}$ \\
\hline $\mathrm{P}$ & \multicolumn{3}{|c|}{ Ns } & \\
\hline $\mathrm{W}$ & \multicolumn{4}{|c|}{ Ns } \\
\hline \multirow[t]{2}{*}{$\mathrm{PxW}$} & \multicolumn{4}{|c|}{$* *$} \\
\hline & \multicolumn{3}{|c|}{ Jumlah daun (helai) Umur 42 hst } & \\
\hline \multirow{2}{*}{$\begin{array}{c}\text { Tingkat } \\
\text { konsentrasi } \\
\text { kolkisin }(\mathrm{ppm})\end{array}$} & \multicolumn{4}{|c|}{ Lama perendaman (jam) } \\
\hline & \multicolumn{2}{|r|}{6} & 9 & 12 \\
\hline 0 & $6.50 \mathrm{bc}$ & $3.92 \mathrm{a}$ & $5.08 \mathrm{ab}$ & $4.25 \mathrm{a}$ \\
\hline 100 & $5.33 \mathrm{ab}$ & $4.92 \mathrm{ab}$ & $5.17 \mathrm{ab}$ & $5.50 \mathrm{ab}$ \\
\hline 300 & $3.92 \mathrm{a}$ & $7.83 \mathrm{c}$ & $5.58 \mathrm{ab}$ & $4.08 \mathrm{a}$ \\
\hline 500 & $5.42 \mathrm{ab}$ & $4.75 \mathrm{a}$ & $4.92 \mathrm{ab}$ & $4.17 \mathrm{a}$ \\
\hline $\mathrm{P}$ & \multicolumn{4}{|c|}{ Ns } \\
\hline $\mathrm{W}$ & & & & \\
\hline $\mathrm{PxW}$ & & & & \\
\hline & Rerata & a daun (hela & ur 84 hst & \\
\hline Tingkat & & Lama Pe & man (jam) & \\
\hline $\begin{array}{l}\text { konsentrasi } \\
\text { kolksisin (ppm) }\end{array}$ & 3 & 6 & 9 & 12 \\
\hline 0 & $12.92 \mathrm{~cd}$ & $7.50 \mathrm{ab}$ & $8.25 \mathrm{ab}$ & $7.92 \mathrm{ab}$ \\
\hline 100 & $10.67 \mathrm{abc}$ & $8.50 \mathrm{ab}$ & $1.50 \mathrm{abc}$ & $11.58 \mathrm{abc}$ \\
\hline 300 & $7.00 \mathrm{a}$ & $15.08 \mathrm{~d}$ & $13.33 \mathrm{bc}$ & $9.17 \mathrm{ab}$ \\
\hline 500 & $11.58 \mathrm{abc}$ & $9.50 \mathrm{abc}$ & $0.75 \mathrm{abc}$ & 11.17 abc \\
\hline $\mathrm{P}$ & & & & \\
\hline $\mathrm{W}$ & & & & \\
\hline $\mathrm{PxW}$ & & & & \\
\hline & Rerata & a daun (hela & ur 98 hst & \\
\hline Tingkat & & Lama Pe & man (jam) & \\
\hline konsentrasi & 3 & 6 & 9 & 12 \\
\hline
\end{tabular}




\begin{tabular}{|c|c|c|c|c|}
\hline \multicolumn{5}{|l|}{ kolksisin (ppm) } \\
\hline 0 & $14.50 \mathrm{abcd}$ & $9.58 \mathrm{abc}$ & $9.03 \mathrm{ab}$ & $8.36 \mathrm{a}$ \\
\hline 100 & $12.75 \mathrm{abcd}$ & $10.17 \mathrm{abcd}$ & $16.58 \mathrm{~d}$ & $12.17 \mathrm{abcd}$ \\
\hline 300 & $8.44 \mathrm{ab}$ & $15.92 \mathrm{~cd}$ & $15.00 \mathrm{bcd}$ & $10.25 \mathrm{abcd}$ \\
\hline 500 & $13.67 \mathrm{abcd}$ & $10.83 \mathrm{abcd}$ & $12.75 \mathrm{abcd}$ & $13.00 \mathrm{abcd}$ \\
\hline $\mathrm{P}$ & \multicolumn{4}{|c|}{ Ns } \\
\hline $\mathrm{W}$ & \multicolumn{4}{|c|}{ Ns } \\
\hline PxW & \multicolumn{4}{|c|}{$* *$} \\
\hline \multicolumn{5}{|c|}{ Rerata Jumlah daun (helai) umur $112 \mathrm{hst}$} \\
\hline Tingkat & \multicolumn{4}{|c|}{ Lama Perendaman (jam) } \\
\hline $\begin{array}{l}\text { konsentrasi } \\
\text { kolksisin (ppm) }\end{array}$ & 3 & 6 & 9 & 12 \\
\hline 0 & $15.67 \mathrm{abcd}$ & $8.72 \mathrm{a}$ & $8.58 \mathrm{a}$ & $9.17 \mathrm{a}$ \\
\hline 100 & $14.50 \mathrm{abcd}$ & $11.83 \mathrm{abc}$ & $20.00 \mathrm{~d}$ & $14.58 \mathrm{abcd}$ \\
\hline 300 & $10.25 \mathrm{ab}$ & $18.08 \mathrm{~cd}$ & $17.00 \mathrm{bcd}$ & $11.25 \mathrm{abc}$ \\
\hline 500 & $14.33 \mathrm{abc}$ & $12.06 \mathrm{abc}$ & $13.42 \mathrm{abc}$ & $15.00 \mathrm{abcd}$ \\
\hline $\mathrm{P}$ & \multicolumn{4}{|c|}{ Ns } \\
\hline $\mathrm{W}$ & \multicolumn{4}{|c|}{ Ns } \\
\hline PxW & \multicolumn{4}{|c|}{$* *$} \\
\hline \multicolumn{5}{|c|}{ Rerata Jumlah daun (helai) umur 126 hst } \\
\hline Tingkat & \multicolumn{4}{|c|}{ Lama Perendaman (jam) } \\
\hline $\begin{array}{l}\text { konsentrasi } \\
\text { kolksisin }(\mathrm{ppm})\end{array}$ & 3 & 6 & 9 & 12 \\
\hline 0 & $16.28 \mathrm{abcd}$ & $10.25 \mathrm{ab}$ & $9.42 \mathrm{a}$ & $9.83 \mathrm{ab}$ \\
\hline 100 & 15.08 abcd & $12.67 \mathrm{abc}$ & $21.67 \mathrm{~d}$ & $15.58 \mathrm{abcd}$ \\
\hline 300 & $11.08 \mathrm{ab}$ & $19.00 \mathrm{~cd}$ & $17.42 \mathrm{bcd}$ & $13.42 \mathrm{abc}$ \\
\hline 500 & 15.67 abcd & $12.83 \mathrm{abc}$ & $15.50 \mathrm{abcd}$ & $16.58 \mathrm{abcd}$ \\
\hline $\mathrm{P}$ & \multicolumn{4}{|c|}{ Ns } \\
\hline $\mathrm{W}$ & \multicolumn{4}{|c|}{ Ns } \\
\hline PxW & \multicolumn{4}{|c|}{$* *$} \\
\hline
\end{tabular}

Keterangan: angka yang diikuti huruf yang sama pada kolom dan baris yang sama tidak berbeda nyata pada uji Jarak Duncan 5\% ; P : tingkat konsentrasi kolkisin, W : lama perendaman

Tabel 2 menunjukkan bahwa secara umum interaksi antara tingkat konsentrasi 100 ppm dengan lama perendaman kolkisin 9 jam dan tingkat konsentrasi 300 ppm dengan lama perendaman kolkisin 6 jam menghasilkan rerata jumlah daun yang lebih tinggi dibanding kombinasi perlakuan lainnya hingga pengamatan umur 126 hst. 
Tabel 3. Rerata jumlah daun tanaman sedap malam $(\mathrm{cm})$ umur 182 hst berdasarkan tingkat konsentrasi dan lama perendaman kolkisin

\begin{tabular}{|c|c|c|}
\hline \multicolumn{2}{|c|}{ Perlakuan } & Rerata Jumlah Daun (helai) \\
\hline \multirow[t]{4}{*}{ Tingkat konsentrasi (ppm) } & 0 & $16.72 \mathrm{a}$ \\
\hline & 100 & $26.60 \mathrm{~b}$ \\
\hline & 300 & $23.86 \mathrm{~b}$ \\
\hline & 500 & $23.85 \mathrm{~b}$ \\
\hline \multirow[t]{4}{*}{ Lama perendaman (jam) } & 3 & $20.60 \mathrm{a}$ \\
\hline & 6 & $21.90 \mathrm{a}$ \\
\hline & 9 & $25.15 \mathrm{a}$ \\
\hline & 12 & $23.37 \mathrm{a}$ \\
\hline \multicolumn{2}{|l|}{$\mathrm{P}$} & $*$ \\
\hline \multicolumn{2}{|l|}{$\mathrm{W}$} & Ns \\
\hline \multicolumn{2}{|l|}{$\mathrm{PxW}$} & Ns \\
\hline
\end{tabular}

Keterangan: angka yang diikuti huruf yang sama pada kolom yang sama tidak berbeda nyata pada uji Jarak Duncan 5\%

Tabel 3 menunjukkan bahwa pemberian kolkisin pada tingkat konsentrasi 100 ppm - 500 ppm menghasilkan rerata jumlah daun tanaman sedap malam yang lebih tinggi dibandingkan dengan tanaman kontrol. Pada umur 182 hst, pemberian kolkhisin pada tingkat konsentrasi 100 ppm menghasilkan rerata jumlah daun yang tidak berbeda nyata dengan tanaman yang diberi kolkisin pada tingkat konsentrasi 300 ppm dan 500 ppm.

\section{Luas daun}

Hasil analisis ragam menunjukkan bahwa interaksi antara tingkat konsentrasi kolkisin dan lama perendaman secara umum memberikan pengaruh nyata pada luas daun tanaman sedap malam yakni dapat dilihat pada umur pengamatan $28,84,98,112$ dan 126 hari setelah tanam (hst). Sementara perlakuan tigkat konsentrasi berpengaruh nyata secara terpisah terhadap luas daun pada umur pengamatan 140, 168, dan 182 hst.

Tabel 4. Rerata luas daun tanaman sedap malam akibat interaksi antara tingkat konsentrasi dan lama perendaman kolkhisin umur 28, 84, 98, 112 dan 126 hst.

\begin{tabular}{|c|c|c|c|c|}
\hline \multicolumn{5}{|c|}{ Rerata Luas Daun $\left(\mathrm{cm}^{2}\right)$ Umur $28 \mathrm{hst}$} \\
\hline \multirow{2}{*}{$\begin{array}{l}\text { Tingkat konsentrasi } \\
(\mathrm{ppm})\end{array}$} & \multicolumn{4}{|c|}{ Lama perendaman (jam) } \\
\hline & 3 & 6 & 9 & 12 \\
\hline 0 & $19.25 \mathrm{ab}$ & $12.15 \mathrm{a}$ & $13.81 \mathrm{a}$ & $12.48 \mathrm{a}$ \\
\hline 100 & $16.02 \mathrm{ab}$ & $15.09 \mathrm{a}$ & $20.10 \mathrm{ab}$ & $16.29 \mathrm{ab}$ \\
\hline 300 & $12.88 \mathrm{a}$ & $39.48 \mathrm{c}$ & $20.58 \mathrm{ab}$ & $18.02 \mathrm{ab}$ \\
\hline 500 & $32.05 \mathrm{bc}$ & $23.88 \mathrm{ab}$ & $18.39 \mathrm{ab}$ & $17.30 \mathrm{ab}$ \\
\hline
\end{tabular}




\begin{tabular}{|c|c|c|c|c|}
\hline $\mathrm{P}$ & \multicolumn{4}{|c|}{ Ns } \\
\hline W & \multicolumn{4}{|c|}{ Ns } \\
\hline PxW & \multicolumn{4}{|c|}{$* *$} \\
\hline \multicolumn{5}{|c|}{ Rerata Luas daun $\left(\mathrm{cm}^{2}\right)$ Umur 84 hst } \\
\hline \multirow{2}{*}{$\begin{array}{c}\text { Tingkat } \\
\text { konsentrasi } \\
\text { kolkisin (ppm) }\end{array}$} & \multicolumn{4}{|c|}{ Lama perendaman (jam) } \\
\hline & 3 & 6 & 9 & 12 \\
\hline 0 & $159.35 \mathrm{abcd}$ & $69.59 \mathrm{a}$ & $67.58 \mathrm{a}$ & $71.69 \mathrm{a}$ \\
\hline 100 & $185.40 \mathrm{bcd}$ & $122.82 \mathrm{abc}$ & $199.69 \mathrm{~cd}$ & $136.89 \mathrm{abc}$ \\
\hline 300 & $72.68 \mathrm{ab}$ & $259.49 \mathrm{~d}$ & $141.59 \mathrm{abc}$ & $100.47 \mathrm{abc}$ \\
\hline 500 & $159.43 \mathrm{abcd}$ & $138.70 \mathrm{abc}$ & $111.24 \mathrm{abc}$ & $128.97 \mathrm{abc}$ \\
\hline $\mathrm{P}$ & \multicolumn{4}{|c|}{ Ns } \\
\hline $\mathrm{W}$ & \multicolumn{4}{|c|}{ Ns } \\
\hline PxW & \multicolumn{4}{|c|}{$* *$} \\
\hline \multicolumn{5}{|c|}{ Rerata Luas Daun $\left(\mathrm{cm}^{2}\right)$ Umur $98 \mathrm{hst}$} \\
\hline \multirow{2}{*}{$\begin{array}{c}\text { Tingkat } \\
\text { konsentrasi } \\
(\mathrm{ppm})\end{array}$} & \multicolumn{4}{|c|}{ Lama perendaman (jam) } \\
\hline & 3 & 6 & 9 & 12 \\
\hline 0 & $191.14 \mathrm{abc}$ & $75.26 \mathrm{a}$ & $77.13 \mathrm{a}$ & $86.20 \mathrm{a}$ \\
\hline 100 & $187.83 \mathrm{abc}$ & $147.92 \mathrm{abc}$ & $231.45 \mathrm{bc}$ & $128.80 \mathrm{ab}$ \\
\hline 300 & $77.04 \mathrm{a}$ & $265.53 \mathrm{c}$ & 160.69 abc & $108.39 \mathrm{ab}$ \\
\hline 500 & 167.39 abc & $158.65 \mathrm{abc}$ & $115.42 \mathrm{ab}$ & $153.35 \mathrm{abc}$ \\
\hline $\mathrm{P}$ & \multicolumn{4}{|c|}{ Ns } \\
\hline $\mathrm{W}$ & \multicolumn{4}{|c|}{ Ns } \\
\hline PxW & \multicolumn{4}{|c|}{$* *$} \\
\hline \multicolumn{5}{|c|}{ Rerata Luas Daun $\left(\mathrm{cm}^{2}\right)$ Umur $112 \mathrm{hst}$} \\
\hline \multirow{2}{*}{$\begin{array}{c}\text { Tingkat } \\
\text { konsentrasi } \\
(\mathrm{ppm})\end{array}$} & \multicolumn{4}{|c|}{ Lama perendaman (jam) } \\
\hline & 3 & 6 & 9 & 12 \\
\hline 0 & $194.08 \mathrm{abc}$ & $83.30 \mathrm{a}$ & $78.87 \mathrm{a}$ & $88.26 \mathrm{a}$ \\
\hline 100 & $202.46 \mathrm{abc}$ & $154.64 \mathrm{abc}$ & $297.41 \mathrm{c}$ & $151.47 \mathrm{ab}$ \\
\hline 300 & $105.53 \mathrm{a}$ & $271.31 \mathrm{bc}$ & $167.83 \mathrm{abc}$ & $120.26 \mathrm{a}$ \\
\hline 500 & $179.44 \mathrm{abc}$ & $194.03 \mathrm{abc}$ & $133.5 \mathrm{ab}$ & $165.41 \mathrm{abc}$ \\
\hline $\mathrm{P}$ & \multicolumn{4}{|c|}{ Ns } \\
\hline $\mathrm{W}$ & \multicolumn{4}{|c|}{ Ns } \\
\hline PxW & \multicolumn{4}{|c|}{$* *$} \\
\hline \multicolumn{5}{|c|}{ Rerata Luas Daun $\left(\mathrm{cm}^{2}\right)$ Umur $126 \mathrm{hst}$} \\
\hline \multirow{2}{*}{$\begin{array}{c}\text { Tingkat } \\
\text { konsentrasi } \\
(\mathrm{ppm})\end{array}$} & \multicolumn{4}{|c|}{ Lama perendaman (jam) } \\
\hline & 3 & 6 & 9 & 12 \\
\hline 0 & $200.54 \mathrm{abc}$ & $93.35 \mathrm{a}$ & $85.12 \mathrm{a}$ & $108.72 \mathrm{a}$ \\
\hline 100 & $212.37 \mathrm{abc}$ & $161.95 \mathrm{ab}$ & $345.15 \mathrm{c}$ & $171.76 \mathrm{ab}$ \\
\hline 300 & $128.69 \mathrm{ab}$ & $281.98 \mathrm{bc}$ & $178.20 \mathrm{ab}$ & $164.15 \mathrm{ab}$ \\
\hline 500 & $212.06 \mathrm{abc}$ & $201.28 \mathrm{abc}$ & $156.13 \mathrm{ab}$ & $203.02 \mathrm{abc}$ \\
\hline $\mathrm{P}$ & \multicolumn{4}{|c|}{ Ns } \\
\hline $\mathrm{W}$ & & & $\mathrm{Ns}$ & \\
\hline $\mathrm{PxW}$ & & & $* *$ & \\
\hline
\end{tabular}

Keterangan: angka yang diikuti huruf yang sama pada kolom dan baris yang sama tidak berbeda nyata pada uji Jarak Duncan 5\% ; P : tingkat konsentrasi kolkisin, W : lama perendaman. 
Tabel 4 menunjukkan bahwa secara umum interaksi antara tingkat konsentrasi 100 ppm dengan lama perendaman kolkisin 9 jam dan tingkat konsentrasi 300 ppm dengan lama perendaman kolkisin 6 jam menghasilkan rerata luas daun yang lebih tinggi dibanding kombinasi perlakuan lainnya.

Tabel 5. Rerata luas daun tanaman sedap malam $\left(\mathrm{cm}^{2}\right)$ umur 140 sampai $182 \mathrm{hst}$ berdasarkan tingkat konsentrasi dan lama perendaman kolkisin

\begin{tabular}{|c|c|c|c|c|c|}
\hline \multicolumn{6}{|c|}{ Rerata Luas Daun $\left(\mathrm{cm}^{2}\right)$ pada Umur ke - (HST) } \\
\hline \multicolumn{2}{|l|}{ Perlakuan } & 140 & 154 & 168 & 182 \\
\hline \multirow{4}{*}{$\begin{array}{l}\text { Tingkat konsentrasi } \\
\text { (ppm) }\end{array}$} & 0 & $134.71 \mathrm{a}$ & $172.57 \mathrm{a}$ & $184.42 \mathrm{a}$ & $206.80 \mathrm{a}$ \\
\hline & 100 & $250.19 \mathrm{~b}$ & $271.40 \mathrm{a}$ & $334.52 \mathrm{~b}$ & $396.64 \mathrm{~b}$ \\
\hline & 300 & $197.51 \mathrm{ab}$ & $211.08 \mathrm{a}$ & $239.01 \mathrm{ab}$ & $323.35 \mathrm{ab}$ \\
\hline & 500 & 215.71ab & $238.65 \mathrm{a}$ & $301.07 \mathrm{ab}$ & $323.62 \mathrm{ab}$ \\
\hline \multirow{4}{*}{$\begin{array}{l}\text { Lama } \\
\text { (jam) }\end{array}$} & 3 & $203.48 \mathrm{a}$ & $232.72 \mathrm{a}$ & $255.57 \mathrm{a}$ & $298.25 \mathrm{a}$ \\
\hline & 6 & $206.46 \mathrm{a}$ & $232.45 \mathrm{a}$ & $248.58 \mathrm{a}$ & $303.05 \mathrm{a}$ \\
\hline & 9 & $218.92 \mathrm{a}$ & $234.96 \mathrm{a}$ & $297.28 \mathrm{a}$ & $329.12 \mathrm{a}$ \\
\hline & 12 & $169.27 \mathrm{a}$ & $193.57 \mathrm{a}$ & $257.59 \mathrm{a}$ & $319.97 \mathrm{a}$ \\
\hline \multicolumn{2}{|l|}{$\mathrm{P}$} & $*$ & $*$ & $*$ & $*$ \\
\hline \multicolumn{2}{|l|}{ W } & $\mathrm{Ns}$ & Ns & Ns & Ns \\
\hline \multicolumn{2}{|l|}{ PxW } & Ns & Ns & Ns & Ns \\
\hline
\end{tabular}

Keterangan: angka yang diikuti huruf yang sama pada kolom yang sama tidak berbeda nyata pada uji Jarak Duncan 5\%

Tabel 5 menunjukkan bahwa pada umur pengamatan 140 hingga 182 hst, pemberian kolkisin pada tingkat konsentrasi $100 \mathrm{ppm}-500 \mathrm{ppm}$ secara umum menghasilkan rerata luas daun tanaman sedap malam yang lebih tinggi dibandingkan dengan tanaman kontrol. Pemberian kolkhisin pada tingkat konsentrasi 100 ppm menghasilkan rerata luas daun yang tidak berbeda nyata dengan tanaman yang diberi kolkisin pada tingkat konsentrasi 300 ppm dan 500 ppm.

\section{Jumlah Anakan}

Hasil analisis ragam menunjukkan bahwa interaksi antara tingkat konsentrasi kolkisin dan lama perendaman memberikan pengaruh nyata pada jumlah anakan tanaman sedap malam. 
Tabel 6. Rerata jumlah anakan tanaman sedap malam akibat interaksi antara tingkat konsentrasi dan lama perendaman kolkhisin.

\begin{tabular}{|c|c|c|c|c|}
\hline \multicolumn{5}{|c|}{ Rerata Jumlah Anakan } \\
\hline \multirow{2}{*}{$\begin{array}{c}\text { Tingkat } \\
\text { konsentrasi } \\
(\mathrm{ppm})\end{array}$} & \multicolumn{4}{|c|}{ Lama perendaman (jam) } \\
\hline & 3 & 6 & 9 & 12 \\
\hline 0 & $2.58 \mathrm{abc}$ & $1.5 \mathrm{a}$ & $1.5 \mathrm{a}$ & $1.75 \mathrm{abc}$ \\
\hline 100 & $1.77 \mathrm{abc}$ & $1.83 \mathrm{abc}$ & $3.48 \mathrm{~cd}$ & $2.08 \mathrm{abc}$ \\
\hline 300 & $1.67 \mathrm{ab}$ & $2.92 \mathrm{bcd}$ & $3.5 \mathrm{~d}$ & $1.92 \mathrm{abc}$ \\
\hline 500 & $2.12 \mathrm{abc}$ & $1.42 \mathrm{a}$ & $2.58 \mathrm{abcd}$ & $2.67 \mathrm{abcd}$ \\
\hline $\mathrm{P}$ & \multicolumn{4}{|c|}{ Ns } \\
\hline W & \multicolumn{4}{|c|}{$*$} \\
\hline PxW & \multicolumn{4}{|c|}{ *** } \\
\hline
\end{tabular}

Keterangan: angka yang diikuti huruf yang sama pada kolom dan baris yang sama tidak berbeda nyata pada uji Jarak Duncan 5\% ; P : tingkat konsentrasi kolkisin, W : lama perendaman

Tabel 6 menunjukkan bahwa lama perendaman memberikan pengaruh nyata terhadap jumlah anakan tanaman sedap malam pada tingkat konsentrasi 100 dan 300 ppm. Pada tingkat konsentrasi $100 \mathrm{ppm}$, lama perendaman 9 jam menghasilkan rerata jumlah anakan yang lebih tinggi dibanding lama perendaman 3, 6 dan 12 jam. Sementara itu pada tingkat konsentrasi kolkisin 300 ppm, lama perendaman 9 jam menghasilkan rerata jumlah anakan yang lebih tinggi dibanding lama perendaman 3 dan 12 jam, namun tidak berbeda nyata dengan jumlah anakan pada lama perendaman 6 jam.

\section{Pembahasan}

Secara umum, hasil penelitian menunjukkan bahwa interaksi tingkat konsentrasi dan lama perendaman kolkisin tidak berpengaruh terhadap panjang tanaman sedap malam. Namun demikian, secara terpisah aplikasi pemberian kolkisin pada tingkat yang beragam yaitu 100 ppm hingga 500 ppm, memberikan pengaruh nyata terhadap rerata panjang tanaman pada umur 70, 98, 126 hingga 146 hst dimana rerata panjang tanaman yang dihasilkan lebih tinggi dibanding kontrol (tanpa kolkisin). Hal ini diduga karena interaksi genetik tanaman dengan kondisi agroekologi daerah penanaman di dataran medium, panjang tanaman sedap malam yang diberi kolkisin memberikan respon pertumbuhan yang lebih tinggi bila dibandingkan dengan tanaman yang tidak direndam dengan kolkisin (kontrol). Hasil ini sejalan dengan hasil penelitian oleh Wiendra et al. (2011) pada tanaman pacar air, dimana pemberian kolkisin memberikan perubahan sifat morfologi pada tinggi tanaman pacar air. Dimana pada 
tanaman pacar air, pada umur 1 bulan setelah tanam, antara tinggi tanaman kontrol dan perlakuan perendaman kolkisin berbeda nyata tetapi antara masing-masing perlakuan perendaman kolkisin tidak berbeda nyata.

Hasil penelitian ini sedikit berbeda dengan hasil poliploidisasi pada tanaman bawang merah hasil peneltian Permadi et al. (1991), dan hasil penelitian Hartati (2000) pada tanaman Hibiscus sp. Hasil penelitian Permadi (1991), interaksi antara konsentrasi kolkisin dengan waktu perendaman menentukan efektivitas induksi poliploidi yang menghasilkan tanaman bawang merah yang lebih pendek, jumlah daun sedikit, jumlah stomata sedikit namun daun lebih tebal dengan pembesaran stomata baik lebar maupun panjang. Dan hasil penelitian Hartati (2000), pada tanaman Hibiscus sp. menunjukkan pengunaan kolkisin menyebabkan terjadinya penyimpangan fase pertumbuhan vegetatif, yaitu dengan menurunnya tinggi tanaman. Suryo (1995) menyatakan bahwa pengaruh perlakuan kolkisin pada tanaman sampai dosis tertentu dapat menyebabkan penambahan ukuran tanaman, namun peningkatan sampai pada dosis yang melebihi kemampuan sel beradaptasi dengan agen penghambat mitosis sel ini dapat berdampak negatif terhadap pertumbuhan sel, sehingga menyebabkan panjang tanaman mengalami penurunan.

Secara umum, interaksi antara tingkat konsnetrasi dan lama perendaman kolkisin memberikan pengaruh nyata pada pertumbuhan vegetatif tanaman sedap malam ditunjukkan pada jumlah daun dan luas daun. Pada tingkat konsentrasi kolkisin 100 ppm dengan lama perendaman 9 jam dan pada tingkat konsentrasi kolkisin 300 ppm dengan lama perendaman kolkisin selama 6 jam pada umbi sedap malam memberikan rerata jumlah daun dan luas daun tanaman sedap malam yang lebih tinggi dibanding perlakuan lainnya. Respon hasil pertumbuhan jumlah daun dapat dilihat pada umur pengamatan 14, 42, 84, 98 hingga 126 hari setelah tanam. Sementara di akhir pengamatan umur 182 hst, pengaruh tingkat konsentrasi kolkisin secara terpisah menunjukkan pengaruh nyata terhadap jumlah daun tanaman sedap malam dimana tanaman yang diberi larutan kolkisin menghasilkan rerata jumlah daun yang lebih tinggi dibanding kontrol. Pada 
pengamatan luas daun menunjukkan hal serupa, dimana interaksi antara tingkat konsentrasi dan lama perendaman kolkisin secara umum memberikan pengaruh nyata terhadap luas daun yang dihasilkan, dapat dilihat pada umur pengamatan 28, 84, 98, 112 dan 126 hst. Sementara di akhir pengamatan umur 140 hingga 182 hst, tingkat konsentrasi kolkisin memberikan pengaruh nyata terhadap luas daun tanaman. Dimana rerata luas daun dari tanaman sedap malam yang diberi kolkisin lebih tinggi dibanding kontrol, meskipun antara masing-masing perlakuan perendaman kolkisin tidak berbeda nyata.

Hasil penelitian ini senada dengan penelitian Herawati (1989) tentang budidaya kepala sari tembakau dengan perlakuan kolkisin, menyatakan bahwa pada plantlet yang diberi perlakuan kolkisin telah terjadi peningkatan jumlah daun, lebar dan panjang luas daun semakin besar. Hasil penelitian pada luas daun tanaman sedap malam ini juga sejalan dengan penelitian Tresina (2008) pada tanaman anggrek C. Pandurata, dimana pemberian kolkisin pada tingkat konsentrasi 0.5 - 15 ppm dan waktu perendaman 1-12 jam menyebabkan luas daun C. Pandurata semakin besar.
Senada pula dengan hasil penelitian Wardiyati et al. (2002), yang menunjukkan bahwa pemberian kolkisin 0.1 ppm pada protocorm anggrek Phalaenopsis amabilis telah memberikan penambahan besar ukuran daun, dan pemberian hingga $1 \mathrm{ppm}$ belum menunjukkan kematian fatal. Semakin besar luas daun, memberikan peluang semakin banyak zat makanan yang dapat diproses didalam daun karena fungsi daun sebagai organ yang bertugas melaksanakan fotosintesi dan menyediakan makanan bagi bagian lain tanaman (Gardner, Pearce dan Mitchell, 1991).

Sementara pada hasil jumlah anakan menunjukkan bahwa pada konsentrasi 300 ppm lama perendaman 9 jam dan 6 jam serta pada konsentrasi 100 ppm dengan lama perendaman 9 jam menghasilkan rerata jumlah anakan yang lebih banyak, secara berurutan yaitu 3.5, 2.99 dan 33.48 anakan. Hal ini diduga berkaitan dengan tunas pada umbi sedap malam yang tersebar disepanjang umbi, sehingga aplikasi konsentrasi dan lama perendaman memberikan pengaruh pada pertumbuhan tunas yang menghasilkan anakan. 
Avery et al. (1947) menyatakan bahwa perubahan yang terjadi pada tanaman akibat pemberian kolkisin bisa bervariasi. Sebagian tanaman mengalami mutasi pada hampir seluruh bagian tanaman mulai titik tumbuh hingga organ generatif, namun sebagian lainnya hanya mengalami mutasi pada beberapa organ saja. Sehingga kolkisin yang diberikan kepada setiap individu tanaman tidak mempengaruhi semua sel tanaman, tetapi hanya sebagian sel-sel saja. Adanya pengaruh yang berbeda pada sel-sel tanaman karena kolkisin hanya efektif pada sel yang sedang aktif membelah.

\section{KESIMPULAN}

Interaksi antara perlakuan tingkat konsentrasi dan lama perendaman kolkisin berpengaruh nyata terhadap perubahan komponen pertumbuhan tanaman meliputi jumlah daun, luas daun, jumlah anakan. Dimana pemberian kolkisin pada tingkat konsentrasi 100 ppm dengan lama perendaman 9 jam dan pada tingkat konsentrasi 300 ppm dengan lama perendaman menghasilkan rerata jumlah daun dan luas daun yang lebih tinggi dibanding perlakuan lainnya, sementara pada jumlah anakan, perlakuan kolkisin pada tingkat konsentrasi 300 ppm dengan lama perendaman 9 jam menghasilkan jumlah anakan yang lebih banyak dibanding perlakuan lainnya meskipun tidak berbeda nyata dengan kedua perlakuan di atas.

Perubahan nyata terjadi pada komponen pertumbuhan dan hasil tanaman sedap malam meliputi panjang tanaman, jumlah daun, luas daun, akibat pemberian kolkisin pada tingkat konsentrasi hingga 500 ppm dibanding pada tanaman yang tidak diberi kolkisin.

\section{DAFTAR PUSTAKA}

Avery Jr., George S. dan E.B. Johnson. 1947. Hormones and horticulture. Mc Graw-Hill Book Co. Inc. New York and London.

Gardner, F.P., R. B. Perace dan R. L. Mitchell. 1991. Fisiologi tanaman Budidaya. Diterjemahkan oleh: herawati Susilo. Penerbit Universitas Indonesia. Jakarta. Pp.428.

Hartati, RR. S. 2000. Penggunaan Colchicin dalam penggandaan kromosom hasil hibridisasi interspesifik pada Hibiscus sp. untuk mengatasi sterilitas F1. Tesis. Universitas Brawijaya. Malang. Tidak dipublikasikan.

Permadi,A.H, R. Cahyani, dan S. Syarif. 1991. Cara pembelahan 
umbi, lama perendaman, dan

konsentrasi kolkhisin pada poliploidisasi bawang merah 'Sumenep'. Zuriat.Vol 2:17-26.

Plantus. 2008. Budidaya dan perbanyakan umbi sedap malam. http://

balithi.litbang.deptan.go.id.

Sulistianingsih, R., Suyanto, ZA., dan N. Anggia, E. 2004. Peningkatan kualitas anggrek Dendrobium hibrida dengan pemberian kolkhisin. Ilmu Pertanian. 11(1):13-21.

Suryo. 1995. Sitogenetika. Gadjah Mada University Press.Yogyakarta. pp.217-226.

Tresina. 2008. Pengaruh tingkat konsentrasi dan waktu perendaman colchicin terhadap morfologi dan genetik anggrek hitam (Coelogyne pandurata). Tesis. Universitas Brawijaya Malang. Tidak dipublikasikan.

Wardiyati, T.D. Saptadi, S. Soedjono dan D. Widiastuti. 2002. Pengaruh colchicin dan radiasi sinar gamma terhadap pertumbuhan vegetatif anggrek bulan. Agrivita 24(2):80-88.

Wiendra, Ni Made S., M. Pharmawati dan Ni Putu A. Astiti. 2011. Pemberian kolkhisin dengan lama perendaman berbeda pada induksi poliploidi tanaman Pacar Air (Impatient balsamina L.) 